\title{
ASSESSMENT OF ENAMEL DECALCIFICATION IN ORTHODONTIC PATIENTS.
}

\author{
${ }^{1}$ Mukesh Kumar, Sommya Kumari, ${ }^{3}$ Ambuj Chandna, Dhirendra Pratap Singh ${ }^{5}$ Rameshwar Singh \\ ${ }^{1}$ Vardhman Institute of Medical Sciences, Pawapuri, Nalanda, Bihar. \\ ${ }^{2}$ Buddha Institute of Dental Sciences and Hospital, Patna, Bihar. \\ ${ }^{3}$ D.J. College of Dental Sciences and Research, Modinagar, Uttar Pradesh. \\ ${ }^{4}$ Chandra Dental College and Hospital, Uttar Pradesh. \\ ${ }^{5}$ Vardhman Institute of Medical Sciences, Pawapuri, Nalanda, Bihar. .
}

\section{Research Article}

\section{Key words:}

Fixed orthodontic appliance, oral hygiene, plaque, white spot lesion.

Source of support : Nil

Conflict of interest: None
INTRODUCTION: Enamel decalcification in the form of white spot lesion (WSL) is a common side effect seen in patients with fixed orthodontic appliances. Review of literature on prevalence of WSL associated with orthodontic treatment showed various reports ranging from $2 \%$ to 97\%.[1-3] The occurrence of white spot lesion is related to increased susceptibility of plaque accumulation and retention on tooth surface around the orthodontic brackets and auxiliaries of the fixed orthodontic appliance system. The cleansing of such areas requires extra time and effort by the patient using additional cleansing aids, frequent motivation and reinforcement by the orthodontist.

The white spot lesion has been defined as the subsurface enamel porosity from carious demineralization that presents itself as a milky white opacity when located on smooth surfaces.[4] This surface retains its ability to be remineralized with the shift in environment to increase in fluoride availability and decrease in plaque accumulation.
When there is unfavorable condition of increased duration of plaque retention, such white lesions cause break in the enamel surface continuity leading to cavitation. [5-6] The present study aims to determine the prevalence of white spot lesion among fixed orthodontic patients and compare with the untreated normal subjects. The study also attempts to compare the occurrence of WSL among the patients with lesser and higher duration of fixed orthodontic treatment and compare the occurrence of WSL between gender groups.

\section{MATERIALS AND METHOD:}

The cross sectional study was conducted at Vardhman Institute of Medical Sciences, Pawapuri, to determine the prevalence of white spot lesion among orthodontic patients and non-orthodontic subjects. The study was approved by the institutional research committee. 
The purposive sampling was done to compare the prevalence of WSL of 100 orthodontic patients (study group) with 100 untreated subjects (control group). The study group was further divided in to two categories based on the treatment duration of 6-18 months and more than 18 months to assess the occurrence of WSL between two categories. All subjects were within the age range of 13-30 years representing both genders. The study group comprised of orthodontic patients with fixed appliance of 0.018 " MBT brackets in both arches. The subjects comprised of all types of malocclusions with more than 6 months of treatment duration. The control group comprised of similar age cohorts with normal occlusion or varying degree of malocclusion without the previous history of orthodontic treatment.

The teeth considered for examination were second premolar to second premolar in both maxillary and mandibular arches. Molars were excluded from the study as many molar teeth were banded obviating the visibility for WSL. The missing teeth were not considered in the study. The informed written consent was taken from the subjects before examination. The teeth were visually examined on the buccal surface after removing plaque with the help of instruments and air water spray drying. Gorelick's WSL index[1] was used to determine the white spot lesion. Examination was done in the dental chair with good illumination.

Data analysis was done using SPSS version 10.0 software program. Descriptive statistics were calculated and independent Student's t-test was used to compare the difference between the groups. The $\mathrm{p}<0.05$ was considered significant and confidence level was predetermined at $95 \%$.

\section{CONCLUSION:}

The present study agrees with various other studies that the fixed orthodontic treatment increase the risk of white spot lesion in mild to moderate form, seldom leads to cavitations. The occurrence of WSL is significantly higher in fixed orthodontic patients as compared to nontreated subjects.

\section{RESULT:}

The samples comprised of 100 orthodontic patients and 100 untreated subjects. The orthodontic subjects with treatment duration 6-18 months were 50 and more than 18 months were 50 in number. The mean age of the orthodontic subjects was 19.19 years (SD 4.515) and the mean is of non-orthodontic subjects was 19.63 years (SD 4.069). The female subjects were 185 and male were 115 among the orthodontic subjects.

Descriptive statistics of mean, standard deviation and range of the number of teeth affected with white spot lesion among non-orthodontic and orthodontic groups is given in Table 1.

\begin{tabular}{|l|l|l|l|l|}
\hline Table 1: Descriptive Statistics of number of teeth involved with WSL. \\
\hline Group & Number (n) & Mean & SD & Range \\
\hline Untreated non-orthodontic & 100 & 0.65 & 1.925 & $0-13$ \\
\hline 6-18 months orthodontic & 50 & 1.04 & 1.621 & $0-9$ \\
\hline & & & & \\
\hline$>18$ months orthodontic & 50 & 2.71 & 3.180 & $0-20$ \\
\hline Total orthodontic & 100 & 2.40 & 3.080 & $0-20$ \\
\hline
\end{tabular}

The prevalence of WSL in orthodontic patients was 54.3\%; among them prevalence was $40 \%$ in 6-18 months treatment duration group and $68.7 \%$ in more than 18 months treatment duration group (Table 2). Table 2 also depicts the number of cases affected with WSL with respect to extent of teeth.

\begin{tabular}{|c|c|c|c|c|c|c|}
\hline \multicolumn{7}{|c|}{ Table 2: Occurrence and extent of WSL } \\
\hline \multirow[t]{2}{*}{ Group } & \multirow[t]{2}{*}{$\mathrm{n}$} & \multicolumn{2}{|c|}{ Occurrence of WSL } & \multicolumn{3}{|c|}{ Extent of WSL } \\
\hline & & $\mathrm{n}$ & $\%$ & 1 tooth & $2-4$ teeth & $>4$ teeth \\
\hline Untreated non-orthodontic & 100 & 20 & 20 & $7(35 \%)$ & $8(40 \%)$ & $5(25 \%)$ \\
\hline 6-18 months orthodontic & 150 & 60 & 60 & $15(25 \%)$ & $38(63 \%)$ & $7(11.21 \%)$ \\
\hline$>18$ months orthodontic & 150 & 103 & 68.7 & $16(15.5 \%)$ & $55(53.39 \%)$ & $32(31.06 \%)$ \\
\hline Total orthodontic & 300 & 163 & 54.3 & $31(19.01 \%)$ & $93(57.05 \%)$ & $39(23.92 \%)$ \\
\hline
\end{tabular}

The study found statistically significant difference between untreated group and orthodontically treated group with respect to the number of teeth affected with WSL (Table 3). Similarly, there was a significant difference between the categories of orthodontic patients of 6-18 months and more than 18 months duration (Table 4). However, there was no significant difference between male and female orthodontic patients with respect to the occurrence of WSL (Table 5).

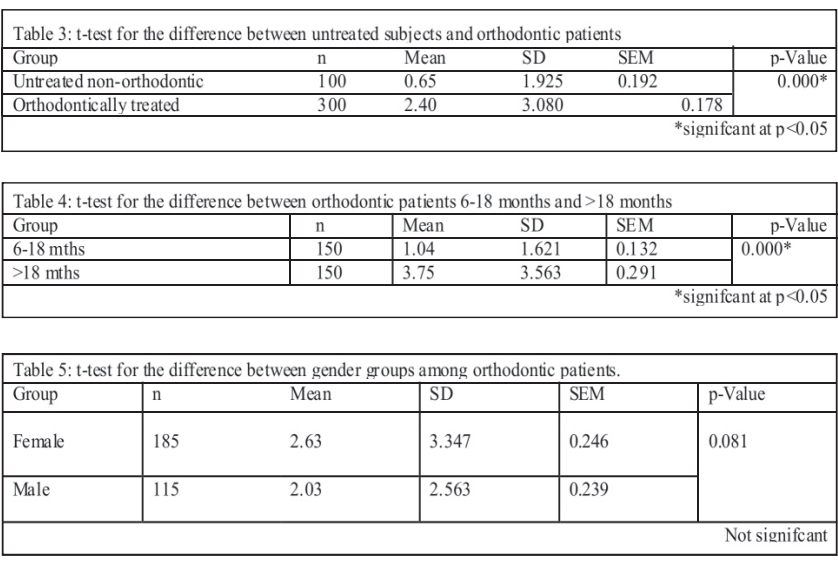

\section{REFERENCES:}

1. Gorelick L, Geiger AM, Gwinnett AJ. Incidence of white spot formation after bonding and banding. Am J Orthod Dentofac Orthop. 1982; 81:93-98.

2. Øgaard B, Larsson E, Henriksson T, Birkhed D, Bishara SE. Effects of combined application of antimicrobial and fuoride varnishes in orthodontic patients. Am J Orthod Dentof Orthop. 2001; 120: 28-35. 
3. Mitchell L. Decalcification during orthodontic treatment with Fixed appliances- An overview. Br J Orthod. 1992; 19:199-205.

4. Summitt JB, Robbins JW, Schwartz RS. Fundamentals of Operative Dentistry: A Contemporary Approach. 2006; 3rd Ed., Hanover Park, IL, Quintessence Pub, p.2-4.

5. Backer Dirks O. Posteruptive changes in dental enamel. J Dent Res. 1966; 45:503-11.

6. Vonder Fehr FR, Loe H, Theilade E. Experimental caries in man. Caries Res. 1970; 4:131-48.

7. Shrestha S, Shrestha L, Shrestha N, Shrestha RM. Effect of orthodontic treatment on occurrence of dental caries. Orthod J Nep. 2013; 3:1:31-36.

8. Hadler-Olsen S, Sandvik K, El-Agroudi MA, Øgaard B. Incidence of caries and white spot lesions in orthodontically treated adolescents with a comprehensive caries prophylactic regimen - A prespective study. Euro J Orthod. 2011; 12:1-7.

9. Boersma JG, van der Veen MH, Lagerweij MD, Bokhout B. Caries prevalence measured with QLF after treatment with Fixed orthodontic appliances: Infuencing factors. Caries Res. 2005; 39:41-47.

10. Forsberg CM, Brattstrom V, Malamberg E, Nord CE. Ligature wires and elastomeric rings: Two methods of ligation, and their association with microbial colonization of streptococcus mutans and lactobacilli. Eur J Orthod. 1991; 13: 416-20.

11. Sukontapatipark W, El-Agroudi MA, Selliseth NJ, Thunold K, Selvig KA. Bacterial colonization associated with Fixed orthodontic appliances. A scanning electron microscopic study. Euro J Orthod. 2001; 23:475-484.

12. Øgaard B, Rolla G, Arends J. Orthodontic appliances and enamel demineralization. Part 1. Lesion development. Am J Orthod DentofacOrthop. 1988; 94:68-73.

13. Øgaard B. Prevalence of white spot lesions in 19year-olds: A study on untreated and orthodontically treated persons 5 years after treatment. Am J Orthod Dentofac Orthop. 1989; 96:423-27.

14. Mizrahi E. Surface distribution of enamel opacities following orthodontic treatment. Am J Orthod. 1983; 84: 323-31.

15. Tufekci E, Dixon JS, Gunsolley JC, Lindauer SJ. Prevalence of white spot lesions during orthodontic treatment with fixed appliances. Angle Orthod. 2011;81:2:206-10.

16. Geiger AM, Gorelick L, Gwinnett AJ, Griswold PG. The effect of a fuoride program on white spot formation during orthodontic treatment. Am J Orthod Dentofac Orthop. 1988; 94:123-128.

\section{CORRESPONDING AUTHOR:}

Dr. Sommya Kumari

Post Graduate Student

Department Of Prosthodontics and Crown \& Bridge

Buddha Institute of Dental Sciences and Hospital

Kankarbagh, Patna, Bihar

Email : Sommyakumari@gmail.com 